\title{
Volatility Persistence in Cryptocurrency Markets Under Structural Breaks
}

\begin{abstract}
:
This paper deals with the analysis of volatility persistence in 12 main cryptocurrencies (Bitcoin, Bitshare, Bytecoin, Dash, Ether, Litecoin, Monero, Nem, Ripple, Siacoin, Stellar and Tether) taking into account the possibility of structural breaks. Using fractional integration methods, the results indicate that both absolute and squared returns display long memory features, with orders of integration confirming the long memory hypothesis. However, after accounting for structural breaks, we find a reduction in the degree of persistence in the cryptocurrency market. The evidence of persistence in volatility imply that market participants who want to make gains across trading scales need to factor the persistence properties of cryptocurrencies in their valuation and forecasting models since that will help improve long-term volatility market forecasts and optimal hedging decisions.
\end{abstract}

JEL Classification: C22; C50; C60; G15; G11; G20

Keywords: Cryptocurrencies; volatility; long memory; fractional integration

Comments from the Editor and two anonymous reviewers are gratefully acknowledged. 


\section{Introduction}

Recent advances in empirical finance research on cryptocurrencies, leading to conclusions on them as a new class of financial assets (Bouri, Jalkh, Molnár, \& Roubaud, 2017; Brandvold, Molnár, Vagstad, \& Valstad, 2015; Corbet, Meegan, Larkin, Lucey, \& Yarovaya, 2018; Glaser, Haferkorn, Weber, \& Zimmermann, 2014; Grinberg, 2012; Katsiampa, 2017; Nadarajah \& Chu, 2017; Urquhart, 2016, 2017; Wu \& Pandey, 2014; Giudici, Milne, \& Vinogradov, 2020; Corbet, Lucey, Urquhart \& Yarovaya, 2019; Aalborg, Molnar, \& de Vries, 2019; Corbet, Larkin, Lucey, Meegan \& Yarovaya, 2020; Platanakis, \& Urquhart, 2019; Alexander \& Dakos, 2020; Gil-Alana, Abakah, \& Rojo, 2020), offer new opportunities for further comprehensive investigation on various aspects of cryptocurrencies yet to be explored. Since the inception of cryptocurrencies in 2009 , research into various aspects of them has experienced increased growth suggesting the significant role of cryptocurrencies to the global financial system. Thus, for example, some papers have focused on the characteristics of cryptocurrencies following different forms of money and other well-known assets (Barber, Boyen, Shi, \& Uzun, 2012; Wu \& Pandey, 2014; etc.). Other papers have concentrated on price formation of cryptocurrencies (Buchholz, Delaney, Warren, \& Parker, 2012; Dyhrberg, 2016; van Wijk, 2013, among others) and interconnections between cryptocurrencies and traditional financial asset class (Corbet et al., 2018). In addition, Gil-Alana, Abakah, \& Rojo (2020) recently provided new evidence on the linkages between cryptocurrencies and stock market indices by showing evidence of no cointegration between cryptocurrencies and stock market indices, which clearly leaves room for further research on cryptocurrencies since they emerged to be decoupled from mainstream finance and economic assets. Interestingly, in spite of the comprehensive emerging literature on cryptocurrencies, a key 
question that remains unanswered is whether they follow the random walk theory, thus whether the behaviour of cryptocurrencies is predictable (Fama, 1970).

In finance and economic literature, a large stream of research modelling financial time series provides strong evidence of persistence in asset returns (Abuzayed, AlFayoumi, \& Molyneux, 2018; Baillie \& Morana, 2009; Caporale, Gil-Alana, Plastun, \& Makarenko, 2016; Charfeddine, 2016; Giraitis, Kokoszka, Leipus, \& Teyssière, 2003; Greene \& Fielitz, 1977). This implies that the market does not respond immediately to information arriving into the financial system, but reacts to it gradually over time. As a result, past price changes can be used to predict future price changes. In this context, shocks to the volatility process tend to have long-lasting effects, thus, providing negative evidence as well as a new perspective to the Efficient Market Hypothesis (EMH). Additionally, a strand of prior studies in economics and finance have focused on estimating time-varying volatility. Indeed, an extensive literature has established the presence of non-constant and time dependent volatility in high-frequency asset returns. The main representatives of this class of model are the autoregressive conditional heteroscedasticity $(\mathrm{ARCH})$ model (Engle, 1982) and its extensions including the generalised ARCH (Bollerslev, 1986) and the fractionally integrated generalised autoregressive conditional heteroscedasticity (FIGARCH) (Baillie, 1996; Baillie, Bollerslev, \& Mikkelsen, 1996). These models explicitly recognise the difference between conditional and unconditional (or long run) variance, where the former is allowed to change over time and the latter remains constant.

Clearly understanding volatility changes in cryptocurrencies is important because, changes in volatility can affect the risk exposure of investors. These changes may alter their respective investments in cryptocurrencies. Thus, understanding volatility dynamics is important for decisions regarding valuation, hedging and investments in physical 
capital tied to cryptocurrencies. Although volatility fluctuates over time, a key question is to determine how persistent these changes are in volatility in prices. This study tries to answer this question. If changes are very persistent, then they will have a major impact on prices of assets that are tied to the price of cryptocurrencies. On the other hand, if changes in volatility are short lived (or less persistent), they should have little or no impact on market variables. Poterba \& Summers (1984) make this point with their asset-pricing model that explicitly shows that the amount of persistence in volatility directly affects the price of an asset. In the current study, we examine volatility persistence in the cryptocurrency market using 12 major CCs, these being Bitcoin, Bitshare, Bytecoin, Dash, Ether, Litecoin, Monero, Nem, Ripple, Siacoin, Stellar and Tether, from 28th April 2013 until 29th March 2018 using fractional integration methods. However, following authors such as Diebold \& Inoue (2001) who showed evidence that long memory and structural breaks are closely interrelated, and Granger \& Hyung (2004) who found that long memory may be partially instigated by the presence of neglected breaks in the series, we additionally investigate the effects of structural breaks on volatility persistence in the 12 cryptocurrencies. We examine the effects of structural breaks because failure to incorporate them may result in an overstatement of the degree of persistence of variance or in spurious estimation of long memory (Lamoureux \& Lastrapes, 1990).

The remaining part of the paper is organized as follows: Section 2 presents a brief overview of the cryptocurrency market along with a summary of the relevant empirical literature on cryptocurrencies. Section 3 describes the methodology adopted in the paper. Section 4 presents the data and the empirical findings, while Section 5 documents the concluding remarks and recommendations for further research. 


\section{Literature review}

Cryptocurrencies have attracted a lot of attention since Bitcoin was first proposed by Nakamoto (2008). Unlike other financial assets, cryptocurrencies are not associated with any higher authority, are infinitely divisible, and their values are based on the security of an algorithm which is able to trace all transaction. The use of cryptocurrencies has grown dramatically in the last decade, mainly due to the low transaction costs, peer-to-peer system, and governmental free design, leading to a surge in trading volume, volatility and price of cryptocurrencies (Corbert et al., 2018). Although Bitcoin is the first decentralised digital currency and remains the cryptocurrency market leader, the number of them is still increasing, reaching 2864 cryptocurrencies traded in April 2020 with a market capitalization of \$201 billion (www.investing.com). Therefore, research in these markets has increased rapidly in order to gain an understanding of several aspects which are key factors for investors to gauge the risks related to an investment in cryptocurrencies, such as, the dynamics of coin creation, competition and destruction in the cryptocurrency industry (Feder et al., 2018), price volatility (Dyhrberg, 2016; Katsiampa, 2017; Sovbetov, 2018), price clustering (Urquhart, 2017), speculation (Cheah and Fry, 2015 ; Yermack, 2015; Blau, 2017), transaction costs (Kim, 2017), the market efficiency (Urquhart, 2016; Nadarajah and Chu, 2017; Bariviera, 2017; Vidal-Tomás, Ibañez and Farinos, 2018), market returns and volatility (Omane-Adjepong et al., 2019), robustness (Charles and Darné, 2019), and persistence in the cryptocurrencies market (Caporale et al., 2018, Bouri, 2018).

In particular, market efficiency of cryptocurrencies is a controversial issue. A market is said to be efficient with respect to an information set if the price would be unaffected by revealing the information set to all market participants (Malkiel, 1992). Economists consider investigating the efficiency of the cryptocurrency market in the 
sense of the Efficient Market Hypothesis (EMH), the classical definition due to Eugene Fama (1970), sorting the efficiency of the market into three segments: strong efficiency, semi-strong efficiency, and weak efficiency. Some authors support that cryptocurrency market, in particular Bitcoin market, is almost efficient (Urquhart (2016), Nadarajah \& Chu (2017), Bariviera (2017), Khuntia \& Pattanayak (2018), Tiwari (2018), Dimitrova (2019)), or inefficient depending on the sample size (Urquhart (2016). In contrast, other authors did not find conclusive evidence that the cryptocurrency market is inefficient, such as Caporale (2019) after examining the day of the week effect in the cryptocurrency market.

On the other hand, some authors showed that their empirical results do not support the EMH for this market. Lo (2004) proposed an alternative to the static view of market efficiency, proposing that the efficiency evolves over time. This is denoted the Adaptive Market Hypothesis (AMH). Urquhart and Hudson (2013), Ito et al. (2014), Noda (2016), Ito et al. (2016), Urquhart and McGroarty (2016) and Yaya et al (2019) investigates the market efficiency with methods derived with the AMH. Furthermore, Chu et al. (2019) investigates the $\mathrm{AMH}$ for the two largest cryptocurrencies, and found evidence that supports the hypothesis of a time varying market efficiency. Two approaches to examine the AMH have been adopted in the literature. One is based on conventional statistical test under the split samples or the rolling-window method (Urquhart (2016), Nadarajah and Chu (2017), Khuntia and Pattanayak (2018), Kristoufek (2018), Chu et al. (2019), Dimitrova et al. (2019), and Vidal-Tomás et al. (2019). However, these methods have the underlying empirical problem of choosing an optimal window width for the test statistics. Unlike these methods, a Generalized Least Square (GLS)-based time-varying model is an approach to examining the $\mathrm{AMH}$, and has the superior property that it does not depend on sample size. In this approach, the degree of market efficiency is measured together 
with its statistical inference. Noda (2020) investigated whether the cryptocurrency markets (Bitcoin and Ethereum) evolve over time, based on Lo's (2004) AMH. The empirical results showed that cryptocurrency market efficiency varies with time, the market efficiency of the BTC is higher than that of the Ethereum in most periods, and the market has been evolving with high market liquidity.

On the other hand, Cheah et al. (2018) model cross market Bitcoin prices as longmemory processes and study dynamic interdependence in a fractionally cointegrated VAR framework. They find long memory in both the individual markets and the system of markets depicting non-homogeneous informational inefficiency. Moreover, Bitcoin markets are found to be fractionally cointegrated, where uncertainty negatively impacts this type of cointegration relationship. Caporale et al. (2018) employs two different longmemory methods (R/S analysis and fractional integration) in the four main cryptocurrencies (Bitcoin, Litecoin, Ripple, Dash) and show that these markets exhibit persistence, and that its degree changes over time. Such predictability represents evidence of market inefficiency and that trend trading strategies may be used to generate abnormal profits in the cryptocurrency market. Most recently, Tran \& Leivirk (2019) have construct a simple measure to quantify the level of market efficiency, called Adjusted Market Inefficiency Magnitude (AMIM). The AMIM increases as market efficiency decreases, and decreases as market efficiency increases. They apply this measure to investigate the level of market efficiency and analyze its variation over time showing that the inefficiency depends also on the period of time and the cryptocurrency (Tran \& Leivirk (in press)). They found that before 2017, cryptocurrency markets are mostly inefficient, but they become more efficient over time in the period 2017-2019. Also, on average, Litecoin is the most efficient cryptocurrency, and Ripple being the least efficient cryptocurrency. 
A summary of the literature review on market efficiency of cryptocurrency is presented in Table 1. 
Table 1: Cryptocurrency Market Efficiency Research

\begin{tabular}{|c|c|c|c|c|c|}
\hline Authors (Year) & Methodology & Data source & Frequency & $\mathrm{N}$ & Observation \\
\hline $\begin{array}{l}\text { Urquhart and } \\
\text { Hudson (2013) }\end{array}$ & $\begin{array}{l}\text { Several Linear and } \\
\text { nonlinear test }\end{array}$ & Not provided & Daily & $>1500$ & $\begin{array}{l}\text { - The linear dependence of } \\
\text { stock returns varies over time but nonlinear } \\
\text { dependence is strong throughout. } \\
\text { - The AMH provides a better description of the } \\
\text { behaviour of stock returns than the EMH }\end{array}$ \\
\hline Urquhart (2016) & Hurst Exponent & bitcoinavarage & Daily & $>1200$ & $\begin{array}{l}\text { - Bitcoin in an inefficient market but may be in the } \\
\text { process of moving towards an efficient market. }\end{array}$ \\
\hline $\begin{array}{l}\text { Nadarajah \& Chu } \\
\quad(2017)\end{array}$ & Ljung-Box and others & Not provided & Daily & $>2000$ & $\begin{array}{l}\text { A power transformation of Bitcoin returns can be } \\
\text { weakly efficient. }\end{array}$ \\
\hline Baur et al (2017) & Means Test & Kaggle.com & Minutely & 3045857 & $\begin{array}{l}\text { - No persistent patterns in returns. } \\
\text { - Persistent patterns in volume, e.g. lower trading } \\
\text { volume on weekends }\end{array}$ \\
\hline $\begin{array}{l}\text { Álvarez-Ramirez et } \\
\quad \text { al. (2018) }\end{array}$ & $\begin{array}{l}\text { Detrended Fluctuation } \\
\text { Analysis (DFA) }\end{array}$ & coindesk.com & $\begin{array}{l}\text { Daily (2013- } \\
\text { 2017) }\end{array}$ & 1435 & $\begin{array}{l}\text { - Bitcoin market exhibits periods of efficiency } \\
\text { alternating with periods where the price dynamics } \\
\text { are driven by anti-persistence. } \\
\text { - Asymmetries and inefficiency are replicated over } \\
\text { different time scales. }\end{array}$ \\
\hline $\begin{array}{l}\text { Caporale et al. } \\
\quad(2018)\end{array}$ & $\begin{array}{l}\mathrm{R} / \mathrm{S} \text { analysis and } \\
\text { fractional integration }\end{array}$ & coinmarketcap & Daily & $>1000$ & $\begin{array}{l}\text { - Cryptocurrency market exhibits persistence (there } \\
\text { is a positive correlation between its past and future } \\
\text { values), and that its degree changes over time. } \\
\text { - Evidence of market inefficiency }\end{array}$ \\
\hline Cheah et al. (2018) & $\begin{array}{l}\text { Two-step Exact Local } \\
\text { Whittle (ELW) } \\
\text { Estimator }\end{array}$ & bitcoincharts & Daily & 1057 & Bitcoin markets are moderate to highly inefficient \\
\hline $\begin{array}{c}\text { Khuntia \& } \\
\text { Pattanayak (2018) }\end{array}$ & $\begin{array}{l}\text { Linear and nonlinear } \\
\text { dependence checked } \\
\text { using rolling-window } \\
\text { approach }\end{array}$ & coindesk.com & Daily & 2714 & $\begin{array}{l}\text { - Market efficiency evolves with time } \\
\text { - Validates the adaptive market hypothesis }(A M H) \text { in } \\
\text { bitcoin market }\end{array}$ \\
\hline Tiwari (2018) & $\begin{array}{l}\text { Centred Moving } \\
\text { Average }\end{array}$ & coindesk.com & Daily & 2525 & Bitcoin market is informational efficient \\
\hline
\end{tabular}




\begin{tabular}{|c|c|c|c|c|c|}
\hline Yonghonga (2018) & Hurst Exponent & bitcoinaverage & Daily (2010-1017) & 2551 & $\begin{array}{l}\text { - long-term memory exists in the Bitcoin market } \\
\text { - high degree of inefficiency ratio } \\
\text { - the Bitcoin market does not become more efficient } \\
\text { over time }\end{array}$ \\
\hline Caporale (2019) & $\begin{array}{c}\text { Average Analysis, } \\
\text { Student's t-test, } \\
\text { ANOVA, the Kruskal- } \\
\text { Wallis test, and } \\
\text { Regression Analysis }\end{array}$ & coinmarketcap.com & Daily & $>1500$ & $\begin{array}{l}\text { - The market exhibits persistence (there is a positive } \\
\text { correlation between its past and future values), and } \\
\text { that its degree changes over time. } \\
\text { - Evidence of market inefficiency }\end{array}$ \\
\hline Noda (2020) & $\begin{array}{l}\text { GLS-based time-varying } \\
\text { autoregressive (TV-AR) }\end{array}$ & coinmarketcap.com & Daily & $\begin{array}{c}2346(\text { Bitcoin }) \\
1515(\text { Ethereum })\end{array}$ & $\begin{array}{l}\text { - The degree of market efficiency varies with time. } \\
\text { - Bitcoin's market efficiency level is higher than that } \\
\text { of Ethereum }\end{array}$ \\
\hline $\begin{array}{c}\text { Tran \&Leirvik (in } \\
\text { press) }\end{array}$ & $\begin{array}{l}\text { Adjusted Market } \\
\text { Inefficiency Magnitude } \\
\text { (AMIM) Model }\end{array}$ & coinmarketcap.com & Daily & $\begin{array}{c}2132 \text { (Bicoin) } \\
607 \text { (EOS) } \\
1301(\text { Ethereum) } \\
2132 \text { (Litecoin) } \\
2034 \text { (Ripple) }\end{array}$ & $\begin{array}{l}\text { - The cryptocurrency-markets become more efficient } \\
\text { over time in the period 2017-2019. } \\
\text { - Litecoin is the most efficient cryptocurrency, and } \\
\text { Ripple being the least efficient cryptocurrency. }\end{array}$ \\
\hline
\end{tabular}


In the context of long memory and volatility in the Bitcoin series, Bariviera et al. (2017) found that the price volatility, measured as the logarithmic difference between intraday high and low prices, exhibits long memory, what reflects a different underlying dynamic process generating prices and volatility. Similarly, Omane-Adjepong et al. (2019) evidenced high persistence in volatility, so that market forecasters are required to account for such persistence characteristics in their forecasting models. This clearly might improve long-term volatility market forecasts and optimal hedging decisions. Moreover, Charfeddine \& Maouchi (2019) questioned the true nature (true versus spurious) of the Long Range Dependence (LRD) behavior observed in the returns and volatility series of four cryptocurrencies. Using a robust approach, they showed that the LRD behavior exhibited by the returns and volatility series of Bitcoin, Litecoin, and Ripple is a true behavior, and not a statistical artifact. As for Ethereum, the results show that the LRD is only supported for the volatility series. Their results confirm the inefficiency of all the considered markets, with the exception of Ethereum. Still on this strand of the literature that examines persistence in cryptocurrency market, Yaya et al (2018) examined other popular alternative coins, by means of fractional integration to analyse persistence and also, using fractional cointegration in a VAR set-up to investigate dependency of the paired variables. Having segregated the series into periods before crash and those after the crash as determined by Bitcoin pricing, they document some interesting results. Thus, higher persistence of the shocks is observed after the crash due to speculation in the mind of cryptocurrency traders, and more evidence of non-mean reversion, implying chances of further price falls in cryptocurrencies. Cointegration analysis between Bitcoin and alternative coins exists during both periods, with weak correlation observed mostly in the post-crash period. In another recent study, Yaya et al (2019) investigated both market efficiency and volatility persistence in twelve cryptocurrencies during pre-crash and post-crash periods. Using robust fractional integration methods in linear and non-linear set-ups, they found that markets of 
Bitcoin and most altcoins considered in their samples are efficient, and highly volatile, particularly in the post-crash sample. The different volatility methods mentioned in the introduction section are summarized in Table 2, and a brief summary of the volatility in cryptocurrency literature review, to the best of our knowledge, is summarized in Table 3.

Table 2: Volatility methods

\begin{tabular}{c|c}
\hline \hline Method & Authors (Year) \\
\hline \hline $\begin{array}{c}\text { Autoregressive conditional heteroscedasticity (ARCH) } \\
\text { model }\end{array}$ & Engle (1982) \\
\hline Generalised ARCH (GARCH) & Bollerslev (1986) \\
\hline $\begin{array}{c}\text { Fractionally integrated generalised autoregressive } \\
\text { conditional heteroscedasticity (FIGARCH) }\end{array}$ & $\begin{array}{c}\text { Baillie (1996); } \\
\text { Baillie, Bollerslev, \& Mikkelsen (1996). }\end{array}$
\end{tabular}

Table 3: Cryptocurrency Volatility Research

\begin{tabular}{|c|c|c|c|c|c|}
\hline $\begin{array}{c}\text { Authors } \\
\text { (Year) }\end{array}$ & Methodology & Data source & Frequency & $\mathrm{N}$ & Observation \\
\hline $\begin{array}{c}\text { Gronwald } \\
(2014)\end{array}$ & GARCH & Mt. Gov. & Daily & $>500$ & $\begin{array}{l}\text { - Bitcoin prices are strongly } \\
\text { characterised by extreme price } \\
\text { movements }\end{array}$ \\
\hline $\begin{array}{c}\text { Dyhrberg } \\
(2016)\end{array}$ & GARCH & "Coindesk.com & Daily & 1769 & $\begin{array}{l}\text { Most aspects of bitcoin are } \\
\text { similar to gold as they } \\
\text { react to similar variables in the } \\
\text { GARCH model, possess similar } \\
\text { hedging capabilities and react } \\
\text { symmetrically to good and bad } \\
\text { news. }\end{array}$ \\
\hline $\begin{array}{c}\text { Bariviera } \\
\text { (2017) }\end{array}$ & $\begin{array}{l}\text { Hurst } \\
\text { Exponent by } \\
\text { means of the } \\
\text { Detrended } \\
\text { Fluctuation } \\
\text { Analysis }\end{array}$ & bitcoincharts & $\begin{array}{l}\text { Daily } \\
(2011- \\
2017)\end{array}$ & 1404 & $\begin{array}{l}\text { - Bitcoin presents large } \\
\text { volatility, but it is reducing over } \\
\text { time. } \\
\text { - long range memory is not } \\
\text { related to market liquidity } \\
\text { - Until } 2014 \text { the time series had } \\
\text { a persistent behavior }(\mathrm{H}>0.5) \text {, } \\
\text { whereas after such date, the } \\
\text { Hurst exponent tended to move } \\
\text { around } 0.5 \text {. }\end{array}$ \\
\hline $\begin{array}{l}\text { Lahmiri et } \\
\text { al. (2018) }\end{array}$ & GARCH & bicoinity & Daily & $>1300$ & $\begin{array}{l}\text { Long-range memory in Bitcoin } \\
\text { market volatility, irrespectively } \\
\text { of distributional inference }\end{array}$ \\
\hline $\begin{array}{l}\text { Omane- } \\
\text { Adjepong } \\
\text { et al. } \\
(2019)\end{array}$ & $\begin{array}{l}\text { ARFIMA- } \\
\text { FIGARCH }\end{array}$ & & Daily & $>900$ & $\begin{array}{l}\text { - Efficiency and volatility } \\
\text { persistence are dependent on } \\
\text { scale and data variations }\end{array}$ \\
\hline
\end{tabular}




\begin{tabular}{|c|c|c|c|c|c|}
\hline $\begin{array}{c}\text { Yaya et al. } \\
\text { (2019) }\end{array}$ & $\begin{array}{l}\text { Fractional } \\
\text { integration } \\
\text { methods in } \\
\text { linear and } \\
\text { nonlinear set } \\
\text { up }\end{array}$ & coinmetrics.io & Daily & $>1100$ & $\begin{array}{l}\text { - Evidence of random walk in } \\
\text { returns of most cryptocurrencies } \\
\text { including Bitcoin. }\end{array}$ \\
\hline
\end{tabular}

\section{Methodology}

In the paper we use long range dependence or long memory methods and in particular we focus on fractional integration. The idea that is behind this technique is that the number of differences required in a time series to convert it in stationary $\mathrm{I}(0)$ may be any real value, and thus, it may potentially include fractional numbers.

In a classical paper by Nelson and Plosser (1982) and using ADF (Dickey and Fuller, 1979) tests, these authors found that fourteen US macro series were integrated of order 1 , or $\mathrm{I}(1)$, implying that first differences were required to convert them stationary $\mathrm{I}(0)$. However, fifteen years later, Gil-Alana and Robinson (1997) examined an updated version of the same dataset, and using fractional integration methods, they found that all except one of the series were in fact $\mathrm{I}(\mathrm{d})$ with the value of $\mathrm{d}$ constrained between 0 and 1 . Since then, this technique has been widely employed in the analysis of aggregated economic and financial data (see, e.g., Lima and Xiao, 2010; Gil-Alana and Moreno, 2012; Mensi et al., 2014; Ben Nasr et al., 2016; Abbritti et al., 2016; Gil-Alana and Mudida, 2018; Merhrdoust and Fallah, 2020; etc.)

The estimation of the differencing parameter $\mathrm{d}$ is conducted by means of using a simple version of the tests of Robinson (1994). These tests are very general, including not only the standard case of fractional integration, but also allowing for seasonal and cyclical differentiation. The functional form of the version of the tests used in this work can be found in Gil-Alana and Robinson (1997). 


\section{Data and Empirical Results}

The data for over 1500 cryptocurrencies was downloaded from CoinMarketCap.com. We followed the conventional literature to select the coins used in the study (e.g., Kaiser, 2019). For the purposes of the study, we included coins that are representative of the cryptocurrency market. First we considered only coins whose market capitalisation was more than the average market value of the cryptocurrency market and had over 850 observations over the period (i.e. the coin should have been in the market for at least for more than 2 years) to be included in the study. Aside, we further ensured the coins formed part of the top 20 cryptocurrencies by market capitalization as of March $31^{\text {st }} 2018$. Descriptive statistics for the coins are given across Tables 4 to 7 .

\section{[Insert Tables 4 - 7]}

From Table 4 Bitcoin seems to be a determinant of the cryptocurrencies market since prices of the other cryptocurrencies peak after the BitCoin price. The standard deviation seems to be approximately twice the mean for most of them except Bytecoin and Tether. The mean returns are moderate for all them at 0.002 across the series. The series have more fat tails (the lowest kurtosis is Siacoin with 7.5 and Tether records the highest at 553). This shows that cryptocurrencies possess an element of heightened unexpected returns (positive/negative) when risk is involved. The best return given by Bitcoin in the market was $30 \%$; Bytecoin however delivered the highest return at 160\% (Table 2). The squared returns (Table 3) project a similar image

We start by estimating $\mathrm{d}$ for each cryptocurrency in the model given by

$$
\mathrm{y}_{\mathrm{t}}=\alpha+x_{\mathrm{t}} ; \quad(1-L)^{d} x_{t}=u_{t}, \quad t=1,2, \ldots,
$$

where $\mathrm{y}_{\mathrm{t}}$ is the series of interest (absolute and squared returns), $\alpha$ is an intercept, and $\mathrm{x}_{\mathrm{t}}$ is an $I(d)$ process where $d$ can be any real value. Thus, $u_{t}$ is $I(0)$ and it will be specified as a white 
noise process (in Table 7) and allowing for autocorrelation (in Table 8). In the latter case we use a non-parametric structure developed by Bloomfield (1973) that approximates ARMA models with very few parameters.

Starting with the case of no autocorrelation we observe that all the estimated values of $\mathrm{d}$ are positive and in the interval $(0,0.5)$ displaying thus a long memory pattern. For the absolute returns, the values of $\mathrm{d}$ range between 0.16 (Siacoin) and 0.32 (Ether), and for the squared returns the values are between 0.11 (Dash) and 0.37 (Ether).

\section{[Insert Tables 7 and 8]}

If autocorrelation is permitted, generally the same conclusion holds in favor of long memory, though in some cases, we cannot reject the null hypothesis of $\mathrm{I}(0)$ or short memory behavior. Thus, for the absolute returns, the estimates of $d$ are all strictly positive except for Ether $(\mathrm{d}=-0.01)$, and for the squared returns short memory is found in the cases of Monero, Nem and Stellar, while for Ether the results support the hypothesis of anti-persistence $(d<0)$. In all the remaining cases, the values of $d$ are once more strictly positive and supporting the long memory hypothesis.

Next we want to investigate if breaks are present in the data and if this is the case, if they have had any influence in the degree of persistence of the data. For this purpose, we use first the approach developed in Bai and Perron (2003) for detecting multiple breaks in time series, and then we also consider the methodology proposed in Gil-Alana (2008), which is basically an extension of Bai and Perron (2008) to the fractional case. The results were practically identical in the two cases the only difference being in the case of Bitshare with the squared returns where two breaks were detected with Bai and Perron (2003) and three with GilAlana's (2008) methodology. The number of breaks and the breaks dates for each case are presented in Table 9.

\section{[Insert Table 9]}


We observe in Table 9 that for the absolute returns, three breaks take place in the cases of Litecoin, Monero, Nem, Siacoin and Stellar; two breaks for Bitcoin, Bitshare, Bytecoin and Ripple; a single break occurs in case of Dash and Ether and no breaks are detected for Tether. For the squared returns, three break dates occur for Bitcoin, Monero and Stellar; two breaks for Bitshare, Bytecoin; on break in case of Dash, Ether, Litecoin and Nem, and no breaks in the remaining three series (Ripple, Siacoin and Tether). With respect to the break dates. Most of them occur at similar dates, namely, the end of 2014 and/or the beginning of 2015; middle or end of 2015 and middle of 2017.

Once the break dates have been determined, we examine the degree of persistence associated with each subsample, and here, based on the shorter sample sizes, we also consider the possibility of a linear trend. Thus, the model examined is now:

$$
\mathrm{y}_{\mathrm{t}}=\alpha+\beta t+x_{\mathrm{t}} ; \quad(1-L)^{d} x_{t}=u_{t}, \quad t=0,1, \ldots,
$$

where $\alpha$ and $\beta$ are the coefficients associated to the intercept and the linear time trend. We estimate $d$ under three set-ups: i) when $\alpha$ and $\beta$ are assumed to be 0 a priori, that is, imposing no deterministic terms in the model, ii) with $\beta=0$ a priori, that is, allowing for an intercept, and iii) allowing for a linear time trend by estimating $\alpha$ and $\beta$ freely from the data. The results in terms of the estimation of $d$ for each of these three cases and each subsample are reported across Table 10 (absolute returns) and Table 11 (squared returns), and we have marked in bold in the tables the most adequate specification for each case according to the significance of the estimated coefficients of these deterministic terms.

Starting with the absolute returns, we observe in Table 10 that the time trend is required in a number of cases such as in the first subsamples for Dash and Litecoin, but also in the last subsamples for Bytecoin, Litecoin and Siacoin. Nevertheless, in the majority of the cases the intercept is sufficient to describe the deterministic part. Table 11 summarizes the estimates of $\mathrm{d}$ for each cryptocurrency and each subsample, and we observe that for the majority of the 
cases, there is a reduction in the degree of persistence as we move from one sample to another. This is noted in the cases of Bitcoin, Bytecoin, Dash, Ether, Ltecoin, Siacoin and Stellar; for Bitshare, Monero, Nem and Stellar, however, the degree of integration seems to be relatively stable, and only for Ripple do we observe an increase in the estimated value of $\mathrm{d}$ across the subsamples.

\section{[Insert Tables $10-13]$}

Table 12 refers to the squared returns. Once more the time trend is required in a number of cases, at the beginning of the sample in the cases of Bitshare, Dash and Litecoin, and during the last subsamples for Bytecoin and Litecoin, and focussing on the estimated values of $\mathrm{d}$, in Table 13, we notice a similar reduction as in the previous case in the degree of persistence in the cases of Bitcoin, Bytecoin, Etter and Nem. However, in other cases such as Dash and Litecoin, we observe a slight increase in the value of $d$.

\section{Concluding comments}

This paper uses fractional integration long-memory techniques and an extended form of Bai and Perron (2003) using fractional integration techniques to investigate the degree of persistence under structural breaks in twelve main cryptocurrencies (Bitcoin, Bitshare, Bytecoin, Dash, Ether, Litecoin, Monero, Nem, Ripple, Siacoin, Stellar and Tether). Succinctly, results obtained under the assumption of no autocorrelation indicate that all the estimated values of $d$ are positive. For the case of autocorrelation, we obtain similar findings suggesting that for all cases the values of $d$ are strictly positive, which clearly supports the long memory hypothesis. This further indicates that the cryptocurrency market is still inefficient implying that abnormal returns could be obtained by investors in the cryptocurrency market through technical trading strategies. After documenting the presence of persistence in the cryptocurrency market, we run further tests to investigate whether structural breaks in the data 
could have any effect on the extent of persistence, and provide some evidence indicating that the degree of persistence is somehow reduced when we take into account structural breaks. We recommend that further research must be carried out to consider the impact of non-linearity effects on the degree of persistence in the cryptocurrency market as expounded by prior studies that examined market efficiency in mainstream financial markets (see for instance, Masten, Coricelli and Masten, 2008; Clements, Franses and Swanson, 2004; Abakah, Alagidede, Mensah and Ohene-Asare, 2018). In fact, Robinson's (1994) tests used in this work impose linearity in the specification of the regression model, and though there exist some extensions of this method allowing for nonlinearities (Cuestas and Gil-Alana, 2016; Yaya et al., 2019a,b) they will be examined in future papers along with other approaches including for example the analysis of cyclical patterns in the context of fractional integration.

The findings documented in this study offer several implications for market participants, investors and policy markets as they seek to make gains, understand the long memory properties and regulate the cryptocurrency market respectively. First, our empirical findings surmise the significance of accounting for the long memory property in an empirical analysis that considers the economics and financial benefits of cryptocurrencies as optimal hedging estimation, risk portfolio management, and potential option valuation. Secondly, the evidence of high persistence in volatility suggests that, market analyst, participants and analysts who aim to make gains in the cryptocurrency market across trading scales need to factor the persistence properties of cryptocurrencies in their valuation and forecasting models since that will help improve long-term volatility market forecasts and optimal hedging decisions. Lastly, the findings also offer market participants and analysts an interesting opportunity to get benefits from the inefficiencies in the cryptocurrency market. As such, they can potentially improve the risk-adjusted performance of their portfolios by using long memory-based frameworks. 


\section{References}

Aalborg, H. A., Molnár, P., \& de Vries, J. E. (2019). What can explain the price, volatility and trading volume of Bitcoin?. Finance Research Letters, 29, 255-265.

Abakah, E. J. A., Alagidede, P., Mensah, L., \& Ohene-Asare, K. (2018). Non-linear approach to Random Walk Test in selected African countries. International Journal of Managerial Finance, 14(3), 362-376.

Abbritti, M., L.A. Gil-Alana, Y. Lovcha and A. Moreno (2016). Term structure persistence, Journal of Financial Econometrics 14, 2, 331-352.

Abuzayed, B., Al-Fayoumi, N., \& Molyneux, P. (2018). Diversification and bank stability in the GCC. Journal of International Financial Markets, Institutions and Money, 57, 1743.

Alexander, C., \& Dakos, M. (2020). A critical investigation of cryptocurrency data and analysis. Quantitative Finance, 20(2), 173-188.

Alvarez-Ramirez, J., Rodriguez, E., \& Ibarra-Valdez, C. (2018). Long-range correlations and asymmetry in the Bitcoin market. Physica A: Statistical Mechanics and its Applications, 492, 948-955.

Alexander, C., \& Dakos, M. (2020). A critical investigation of cryptocurrency data and analysis. Quantitative Finance, 20(2), 173-188.

Baillie, R. T. (1996). Long memory processes and fractional integration in econometrics. Journal of Econometrics, 73(1), 5-59.

Baillie, R. T., Bollerslev, T., \& Mikkelsen, H. O. (1996). Fractionally integrated generalized autoregressive conditional heteroskedasticity. Journal of Econometrics, 74(1), 3-30.

Baillie, R. T., \& Morana, C. (2009). Modelling long memory and structural breaks in conditional variances: An adaptive FIGARCH approach. Journal of Economic Dynamics and Control, 33(8), 1577-1592.

Barber, S., Boyen, X., Shi, E., \& Uzun, E. (2012). Bitter to better-how to make bitcoin a better currency. Paper presented at the International Conference on Financial Cryptography and Data Security.

Bariviera, A. F., Basgall, M. J., Hasperué, W., \& Naiouf, M. (2017). Some stylized facts of the Bitcoin market. Physica A: Statistical Mechanics and its Applications, 484, 82-90.

Baur, D. G., Hong, K. \& Lee, A. D. (2018). Bitcoin: Medium of exchange or speculative assets?. Journal of International Financial Markets, Institutions and Money, 54, 177189. 
Ben Nasr, A., T. Lux, A.N. Ajmi and R. Gupta, (2016), Forecasting the volatility of the Dow Jones Islamic Stock Market Index: Long memory vs. regime switching, International Review of Economics and Finance 45, 559-571

Blau, B. M. (2017). Price dynamics and speculative trading in bitcoin. Research in International Business and Finance, 41, 493-499.

Bloomfield, P. (1973) An exponential model in the spectrum of a scalar time series, Biometrika, 60, 217-226. https://doi.org/10.1093/biomet/60.2.217.

Bollerslev, T. (1986). Generalized autoregressive conditional heteroskedasticity. Journal of Econometrics, 31(3), 307-327.

Bouri, E., Jalkh, N., Molnár, P., \& Roubaud, D. (2017). Bitcoin for energy commodities before and after the December 2013 crash: diversifier, hedge or safe haven? Applied Economics, 49(50), 5063-5073.

Bouri, E., Lau, C. K. M., Lucey, B., \& Roubaud, D. (2018). Trading volume and the predictability of return and volatility in the cryptocurrency market. Finance Research Letters. https://doi.org/10.1016/j.frl.2018.08.01.

Brandvold, M., Molnár, P., Vagstad, K., \& Valstad, O. C. A. (2015). Price discovery on Bitcoin exchanges. Journal of International Financial Markets, Institutions and Money, 36, 1835 .

Buchholz, M., Delaney, J., Warren, J., \& Parker, J. (2012). Bits and bets, information, price volatility, and demand for Bitcoin. Economics, 312.

Caporale, G. M., Gil-Alana, L., \& Plastun, A. (2018). Persistence in the cryptocurrency market. Research in International Business and Finance, 46, 141-148.

Caporale, G. M., Gil-Alana, L., Plastun, A., \& Makarenko, I. (2016). Long memory in the Ukrainian stock market and financial crises. Journal of Economics and Finance, 40(2), 235-257.

Caporale, G. M., \& Plastun, A. (2019). The day of the week effect in the cryptocurrency market. Finance Research Letters, 31, 258-269.

Charfeddine, L. (2016). Breaks or long range dependence in the energy futures volatility: Outof-sample forecasting and VaR analysis. Economic Modelling, 53, 354-374.

Charfeddine, L., \& Maouchi, Y. (2019). Are shocks on the returns and volatility of cryptocurrencies really persistent? Finance Research Letters, 28, 423-430.

Charles, A., \& Darné, O. (2019). Volatility estimation for cryptocurrencies: Further evidence with jumps and structural breaks. Economics Bulletin, 39(2), 954-968.

Cheah, E. T., \& Fry, J. (2015). Speculative bubbles in Bitcoin markets? An empirical investigation into the fundamental value of Bitcoin. Economics Letters 130, 32-36.https://doi.org/10.1016/j.econlet.2015.02.029 
Cheah, E.-T., Mishra, T., Parhi, M., and Zhang, Z. (2018). Long Memory Interdependency and Inefficiency in Bitcoin Markets. Economics Letters, 167, 18-25.

Chu, J., Zhang, Y., \& Chan, S. (2019). The Adaptive Market Hypothesis in the High Frequency Cryptocurrency Market. International Review of Financial Analysis, 64, 221-231.

Clements, M. P., Franses, P. H., \& Swanson, N. R. (2004). Forecasting economic and financial time-series with non-linear models. International Journal of Forecasting, 20(2), 169183.

Corbet, S., Larkin, C., Lucey, B., Meegan, A., \& Yarovaya, L. (2020). Cryptocurrency reaction to FOMC announcements: evidence of heterogeneity based on blockchain stack position. Journal of Financial Stability, 46, 100706.

Corbet, S., Lucey, B., Urquhart, A., \& Yarovaya, L. (2019). Cryptocurrencies as a financial asset: A systematic analysis. International Review of Financial Analysis, 62, 182-199.

Corbet, S., Meegan, A., Larkin, C., Lucey, B., \& Yarovaya, L. (2018). Exploring the dynamic relationships between cryptocurrencies and other financial assets. Economics Letters, $165,28-34$.

Dickey, D.A and Fuller, W. A. (1979) Distributions of the estimators for autoregressive time series with a unit root, Journal of American Statistical Association, 74 (366), 427-481.

Diebold, F. X., \& Inoue, A. (2001). Long memory and regime switching. Journal of Econometrics, 105(1), 131-159.

Dimitrova, V., Fernández-Martínez, M., Sánchez-Granero, M., \& Trinidad Segovia, J. (2019). Some Comments on Bitcoin Market (in)Efficiency. PLOS ONE, 14.

Dyhrberg, A. H. (2016). Bitcoin, gold and the dollar-A GARCH volatility analysis. Finance Research Letters, 16, 85-92.

Engle, R. F. (1982). Autoregressive conditional heteroscedasticity with estimates of the variance of United Kingdom inflation. Econometrica: Journal of the Econometric Society, 987-1007.

Fama, E. F. (1970). Efficient Capital Markets: A Review of Theory and Empirical Work. The Journal of Finance, 25(2), 383-417.

Feder A., Gandal N., Hamrick J.T., Moore T., Vasek M. (2018). The Rise and Fall of Cryptocurrencies, In Proc. of the Workshop on the Economics of Information Security (WEIS) (2018).

Gil-Alana, L., Abakah, E. J. A, \& Rojo, M.F.. (2020). Cryptocurrencies and stock markets indices. Are they related?. Research in International Business and Finance https://doi.org/10.1016/j.ribaf.2019.101063 
Gil-Alana, L.A. and A. Moreno (2012). Uncovering the U.S. term premium.An alternative route. Journal of Banking and Finance, 36, 1184-1193.

Gil-Alana L.A. and R. Mudida (2018), "The Growth Series in Kenya: Evidence of NonLinearities and Factors Behind the Slow Growth," International Journal of Finance and Economics 23, 2, 111-121.

Gil-Alana, L.A. and P.M. Robinson, (1997), Testing of unit roots and other nonstationary hypothesis in macroeconomic time series, Journal of Econometrics 80, 2, 241-268.

Giraitis, L., Kokoszka, P., Leipus, R., \& Teyssière, G. (2003). Rescaled variance and related tests for long memory in volatility and levels. Journal of Econometrics, 112(2), 265294.

Giudici, G., Milne, A., \& Vinogradov, D. (2020). Cryptocurrencies: market analysis and perspectives. Journal of Industrial and Business Economics, 47(1), 1-18.

Glaser, F., Haferkorn, M., Weber, M. C., \& Zimmermann, K. (2014). How to price a digital currency? empirical insights on the influence of media coverage on the bitcoin bubble. Empirical Insights on the Influence of Media Coverage on the Bitcoin Bubble (April 29, 2014). MKWI.

Granger, C. W., \& Hyung, N. (2004). Occasional structural breaks and long memory with an application to the S\&P 500 absolute stock returns. Journal of Empirical Finance, 11(3), $399-421$.

Greene, M. T., \& Fielitz, B. D. (1977). Long-term dependence in common stock returns. Journal of Financial Economics, 4(3), 339-349.

Grinberg, R. (2012). Bitcoin: An innovative alternative digital currency. Hastings Sci. \& Tech. $L J, 4,159$.

Gronwald, M. (2014). The economics of bitcoins-market characteristics and price jumps. CESifo Working Paper Series No. 5121. Available at SSRN: https://ssrn.com/abstract=2548999.

Ito, M., Noda, A., \& Wada, T. (2014). International Stock Market Efficiency: A NonBayesian Time-Varying Model Approach, Applied Economics, 46, 2744-2754.

Ito, M., Noda, A., \& Wada, T. (2014). The Evolution of Stock Market Efficiency in the US: A Non-Bayesian Time-Varying Model Approach,” Applied Economics, 48, 621-635.

Kaiser, L. (2019). Seasonality in cryptocurrencies. Finance Research Letters, 31.

Katsiampa, P. (2017). Volatility estimation for Bitcoin: A comparison of GARCH models. Economics Letters, 158, 3-6.

Khuntia, S. \& Pattanayak, J. K. (2018). Adaptive market hypothesis and evolving predictability of bitcoin. Economics Letters, 167, 26-28. 
Kim, T. (2017). On the transaction cost of Bitcoin. Finance Research Letters, 23, 300-305.

Kristoufek, L. (2018). On Bitcoin Markets (in)Efficiency and its Evolution. Physica A: Statistical Mechanics and its Applications, 503, 257-262.

Lahmiri, S. \& Bekiros S. (2018). Chaos, randomness and multi-fractality in Bitcoin market. Chaos, Solitons \& Fractals, 106, 28-34.

Lamoureux, C. G., \& Lastrapes, W. D. (1990). Persistence in variance, structural change, and the GARCH model. Journal of Business \& Economic Statistics, 8(2), 225-234.

Lima, L.R. and Z. Xiao, (2010), Is there long memory in financial time series?, Applied Financial Economics 20, 6, 487-500.

Lo, A. W. (2004). The Adaptive Markets Hypothesis: Market Efficiency from an Evolutionary Perspective. Journal of Portfolio Management, 30, 15-29.

Malkiel B. (1992). Efficient Market Hypothesis, in Newman, P., M. Milgate, and J. Eatwell (eds), New Palgrave Dictionary of Money and Finance, Macmillan, London.

Masten, A. B., Coricelli, F., \& Masten, I. (2008). Non-linear growth effects of financial development: Does financial integration matter?. Journal of International Money and Finance, 27(2), 295-313.

Mensi, W., S. Hammoudeh and S.M. Yoon (2014), Structural breaks and long memory in modeling and forecasting volatility of foreign exchange markets of oil exporters: The importance of scheduled and unscheduled news announcements, International Review of Economics and Finance 30, 101-119.

Merhrdoust, F. and S. Fallah, (2020), Long memory version of stochastic volatility jumpdiffusion model with stochastic intensity, Estudios de Economia Aplicada 38, 2.

Nadarajah, S., \& Chu, J. (2017). On the inefficiency of Bitcoin. Economics Letters, 150, 6-9.

Nakamoto, S. (2008). Bitcoin: A peer-to-peer electronic cash system. Cryptography Mailing list at https://metzdowd.com.

Nelson, C.R. and C.I. Plosser, (1982), Trends and random walks in macroeconomic time series: Some evidence and implications, Journal of Monetary Economics 10, 2 139-162.

Noda, A. (2020). On the time-varying efficiency of cryptocurrency markets. arXiv preprint arXiv:1904.09403v3.

Omane-Adjepong, M., Alagidede, P., \& Akosah, N. K. (2019). Wavelet time-scale persistence analysis of cryptocurrency market returns and volatility. Physica A: Statistical Mechanics and its Applications, 514, 105-120.

Platanakis, E., \& Urquhart, A. (2019). Should investors include bitcoin in their portfolios? a 
portfolio theory approach. The British Accounting Review, 100837.

Poterba, J. M., \& Summers, L. H. (1984). The persistence of volatility and stock market fluctuations. In: National Bureau of Economic Research Cambridge, Mass., USA.

Sovbetov, Y. (2018). Factors influencing cryptocurrency prices: Evidence from bitcoin, ethereum, dash, litcoin, and monero. Journal of Economics and Financial Analysis, 2(2), 1-27.

Tiwari, A. K., Jana, R., Das, D., \& Roubaud, D. (2018), Informational Efficiency of BitcoinAn Extension. Economics Letters, 163, 106-109.

Tran,V.L., \& Leirvik,T. (2019). A simple but powerful measure of market efficiency. Finance Research Letters, 29, 141-151.

Tran,V.L., \& Leirvik,T. (in press). Efficiency in the markets of crypto-currencies. Finance Research Letters.

Urquhart, A. \& Hudson, R. (2013). Efficient or adaptive markets? Evidence from major stock markets using very long run historic data. International Review of Financial Analysis, $28,130-142$.

Urquhart, A., \& McGroarty, F. (2016). Are stock markets really efficient? Evidence of the adaptive market hypothesis. International Review of Financial Analysis, 47, 39-49.

Urquhart, A. (2016). The inefficiency of Bitcoin. Economics Letters, 148, 80-82.

Urquhart, A. (2017). Price clustering in Bitcoin. Economics Letters, 159, 145-148.

van Wijk, D. (2013). What can be expected from the BitCoin. Erasmus Universiteit Rotterdam.

Vidal-Tomás, D., Ibáñez, A. M., \& Farinós, J. E. (2019). Herding in the cryptocurrency market: CSSD and CSAD approaches. Finance Research Letters, 30, 181-186.

Vidal-Tomás, D., Ibáñez, A. M., \& Farinós, J. E. (2019). Weak Efficiency of the Cryptocurrency Market: a Market Portfolio Approach. Applied Economics Letters, 26, $1627-1633$.

Wu, C. Y., \& Pandey, V. K. (2014). The value of Bitcoin in enhancing the efficiency of an investor's portfolio. Journal of Financial Planning, 27(9), 44-52.

Yaya, O. S., Ogbonna, E. A., \& Mudida, R. (2019). Market Efficiency and Volatility Persistence of Cryptocurrency during Pre-and Post-Crash Periods of Bitcoin: Evidence based on Fractional Integration. MPRA Paper No. 91450, posted UNSPECIFIED. Online at https://mpra.ub.uni-muenchen.de/91450/1/MPRA_paper_91450.pdf

Yaya, O. S., Ogbonna, E. A., \& Olubusoye, O. E. (2018). How Persistent and Dependent are Pricing of Bitcoin to other Cryptocurrencies Before and After 2017/18 Crash? MPRA 
Paper No. 91253, posted UNSPECIFIED. Online at https://mpra.ub.unimuenchen.de/91253/1/MPRA_paper_91253.pdf

Yermack D. (2015), Is bitcoin a real currency? An economic appraisal, Handbook of Digital Currency, Bitcoin, Innovation, Financial Instruments and Big Data, p. 3143.https://doi.org/10.1016/B978-0-12-802117-0.00002-3

Yonghong J., He, N., \& Weihua, R. (2018). Time-varying long-term memory in Bitcoin market. Finance Research Letters, 25, 280-284.

Table 4: Descriptive statistics on the cryptocurrencies

\begin{tabular}{ccccccccc}
\hline & $\begin{array}{c}\text { Average } \\
\text { market } \\
\text { Price }\end{array}$ & \multicolumn{2}{c}{ Highest Price } & \multicolumn{2}{c}{ Lowest Price } & & & \\
Series & Amount & Date(s) & Amount & Date(s) & St. dev & Skew. & Kurt. \\
\hline Bitcoin & $1,649.011$ & $19,497.400$ & $2017-12-16$ & 68.430 & $2013-07-05$ & $3,142.134$ & 3.092 & 12.590 \\
Ethereum & 168.441 & $1,396.420$ & $2018-01-13$ & 0.435 & $2015-10-20$ & 280.518 & 2.028 & 6.571
\end{tabular}




\begin{tabular}{lcccccccc} 
Ripple & 0.114 & 3.380 & $2018-01-07$ & 0.003 & $2014-07-06$ & 0.334 & 5.121 & 35.356 \\
Litecoin & 23.799 & 1.160 & $2017-12-18$ & 358.340 & $2015-01-14$ & 52.081 & 3.489 & 15.474 \\
Stellar & 0.039 & 0.896 & $2018-01-03$ & 0.001 & $2014-11-18$ & 0.114 & 3.836 & 18.125 \\
Monero & 39.515 & 469.200 & $2017-12-20$ & 0.224 & $2015-01-14$ & 87.622 & 2.779 & 10.045 \\
Dash & 103.756 & $1,550.850$ & $2017-12-20$ & 0.315 & $2014-02-15$ & 230.785 & 2.994 & 12.399 \\
tether & 1.000 & 1.210 & $2015-02-26$ & 0.606 & $2015-03-03$ & 0.022 & -9.513 & 215.963 \\
NEM & 0.118 & 1.840 & $2018-01-07$ & 0.000 & $2015-08-25$ & 0.256 & 3.478 & 17.097 \\
Siacoin & 0.039 & 0.094 & $2018-01-06$ & 0.000 & $2015-12-28$ & 0.011 & 3.802 & 21.584 \\
BitShares & 0.056 & 0.892 & $2018-01-03$ & 0.003 & $2016-01-08$ & 0.120 & 3.544 & 17.633 \\
Bytecoin & 0.056 & 0.017 & $2018-01-06$ & 0.000 & $2015-01-03$ & 0.002 & 3.934 & 23.644 \\
\hline
\end{tabular}


Table 5: Descriptive for the Absolute returns

\begin{tabular}{lrrrrrrrr}
\hline \multicolumn{1}{c}{ Series } & \multicolumn{1}{c}{ Start } & Size & Mean & St. Dev. & Skew. & Kurt. & Min. & Max. \\
\hline Bitcoin & 28-Apr-13 & 1796 & 0.002 & 0.045 & -0.193 & 10.872 & -0.266 & 0.357 \\
BitShare & 21-Jul-14 & 1347 & 0.002 & 0.081 & 1.037 & 10.106 & -0.392 & 0.520 \\
Ripple & 4-Aug-13 & 1698 & 0.003 & 0.080 & 2.025 & 29.884 & -0.616 & 1.027 \\
Bytecoin & 17-Jun-14 & 1381 & 0.003 & 0.116 & 2.772 & 34.753 & -0.629 & 1.598 \\
Dash & 14-Feb-14 & 1504 & 0.005 & 0.085 & 3.036 & 43.402 & -0.468 & 1.271 \\
Ethereum & 7-Aug-15 & 965 & 0.005 & 0.084 & -3.544 & 65.362 & -1.302 & 0.412 \\
Litecoin & 28-Apr-13 & 1796 & 0.002 & 0.070 & 1.798 & 28.080 & -0.514 & 0.829 \\
Monero & 21-May-14 & 1407 & 0.003 & 0.078 & 0.663 & 8.644 & -0.378 & 0.585 \\
NEM & 1-Apr-15 & 1093 & 0.006 & 0.094 & 1.868 & 18.151 & -0.361 & 0.996 \\
Siacoin & 26-Aug-15 & 945 & 0.006 & 0.114 & 0.943 & 7.519 & -0.486 & 0.596 \\
Stellar & 5-Aug-14 & 1332 & 0.003 & 0.085 & 1.989 & 17.378 & -0.366 & 0.723 \\
Tether & 25-Feb-15 & 1123 & 0.000 & 0.026 & -10.147 & 553.236 & -0.691 & 0.500 \\
\hline
\end{tabular}


Table 6: Descriptive for the Squared Returns (daily)

\begin{tabular}{lcccccc}
\hline Series & Mean & Std. Dev. & Skewness & Kurtosis & Minimum & Maximum \\
\hline Bitcoin & 0.002 & 0.006 & 8.807 & 121.281 & 0.000 & 0.128 \\
Bitshare & 0.007 & 0.020 & 7.106 & 66.932 & 0.000 & 0.270 \\
Ripple & 0.001 & 0.035 & 19.154 & 510.493 & 0.000 & 1.055 \\
Bytecoin & 0.013 & 0.078 & 25.747 & 803.705 & 0.000 & 2.553 \\
Dash & 0.007 & 0.048 & 27.018 & 871.275 & 0.000 & 1.614 \\
Ether & 0.007 & 0.056 & 28.437 & 854.668 & 0.000 & 1.695 \\
Litecoin & 0.005 & 0.025 & 16.490 & 365.954 & 0.000 & 0.687 \\
Monero & 0.006 & 0.017 & 9.437 & 139.042 & 0.000 & 0.342 \\
Nem & 0.009 & 0.037 & 18.247 & 446.673 & 0.000 & 0.991 \\
Siacoin & 0.013 & 0.034 & 5.486 & 40.898 & 0.000 & 0.355 \\
Stellar & 0.007 & 0.030 & 11.340 & 161.430 & 0.000 & 0.523 \\
Tether & 0.001 & 0.016 & 26.563 & 740.428 & 0.000 & 0.477 \\
\hline
\end{tabular}


Table 7: Estimates of $\mathbf{d}$ in a model under no autocorrelation

\begin{tabular}{|c|c|c|c|}
\hline \multicolumn{2}{|c|}{ ABSOLUTE returns } & \multicolumn{2}{|c|}{ SQUARED returns } \\
\hline Series & d $(95 \%$ band $)$ & Series & d $(95 \%$ band $)$ \\
\hline Bitcoin & $0.21 \quad(0.18,0.25)$ & Bitcoin & $0.15 \quad(0.12,0.19)$ \\
\hline Bitshare & $0.24 \quad(0.21,0.29)$ & Bitshare & $0.17 \quad(0.14,0.23)$ \\
\hline Bytecoin & $0.20 \quad(0.16, \quad 0.25)$ & Bytecoin & $0.12\left(\begin{array}{lll}0.08, & 0.17)\end{array}\right.$ \\
\hline Dash & $0.23(0.20, \quad 0.27)$ & Dash & $0.11 \quad(0.07,0.15)$ \\
\hline Ether & $0.32(0.24,0.42)$ & Ether & $0.37 \quad(0.27, \quad 0.52)$ \\
\hline Litecoin & $0.24 \quad(0.20, \quad 0.28)$ & Litecoin & $0.16(0.13,0.20)$ \\
\hline Monero & $0.21 \quad(0.17, \quad 0.27)$ & Monero & $0.28 \quad(0.22, \quad 0.35)$ \\
\hline Nem & $0.17 \quad(0.13,0.22)$ & Nem & $0.06(0.01,0.11)$ \\
\hline Ripple & $0.27 \quad(0.24, \quad 0.30)$ & Ripple & $0.18 \quad(0.15,0.22)$ \\
\hline Siacoin & $0.16 \quad(0.12,0.22)$ & Siacoin & $0.16(0.11,0.23)$ \\
\hline Stellar & $0.25(0.21, \quad 0.31)$ & Stellar & $0.14 \quad(0.09,0.20)$ \\
\hline Tether & $0.29 \quad(0.25,0.34)$ & Tether & $0.17 \quad(0.12,0.22)$ \\
\hline
\end{tabular}

In parenthesis, the $95 \%$ confidence band of the non-rejection values of $\mathrm{d}$. 
Table 8: Estimates of $d$ in a model under autocorrelation

\begin{tabular}{|c|c|c|c|}
\hline \multicolumn{2}{|c|}{ ABSOLUTE returns } & \multicolumn{2}{|c|}{ SQUARED returns } \\
\hline Series & d $(95 \%$ band $)$ & Series & d $(95 \%$ band $)$ \\
\hline Bitcoin & $0.25(0.21,0.32)$ & Bitcoin & $0.15(0.11,0.22)$ \\
\hline Bitshare & $0.23(0.18,0.28)$ & Bitshare & $0.13\left(\begin{array}{lll}0.07, & 0.19)\end{array}\right.$ \\
\hline Bytecoin & $0.16(0.11,0.22)$ & Bytecoin & $0.09 \quad(0.02, \quad 0.15)$ \\
\hline Dash & $0.17 \quad(0.13,0.23)$ & Dash & $0.06 \quad\left(\begin{array}{lll}0.02, & 0.11)\end{array}\right.$ \\
\hline Ether & $-0.01(-0.07, \quad 0.07)$ & Ether & $-0.15(-0.19,-0.07)$ \\
\hline Litecoin & $0.25(0.21,0.31)$ & Litecoin & $0.13(0.09,0.19)$ \\
\hline Monero & $0.15 \quad(0.10,0.22)$ & Monero & $0.01(-0.03,0.08)$ \\
\hline $\mathrm{Nem}$ & $0.18 \quad(0.12, \quad 0.27)$ & $\mathrm{Nem}$ & $0.05(-0.02,0.14)$ \\
\hline Ripple & $0.35 \quad(0.30,0.42)$ & Ripple & $0.28 \quad\left(\begin{array}{lll}0.22, & 0.35)\end{array}\right.$ \\
\hline Siacoin & $0.17 \quad(0.11,0.25)$ & Siacoin & $0.13\left(\begin{array}{lll}0.07, & 0.21)\end{array}\right.$ \\
\hline Stellar & $0.21 \quad(0.15, \quad 0.29)$ & Stellar & $0.04(-0.01,0.12)$ \\
\hline Tether & $0.29 \quad(0.24, \quad 0.35)$ & Tether & $0.10 \quad(0.05,0.16)$ \\
\hline
\end{tabular}

In parenthesis, the $95 \%$ confidence band of the non-rejection values of $\mathrm{d}$. 


\begin{tabular}{|c|c|c|c|c|c|}
\hline \multicolumn{6}{|c|}{ Table 9: Bai and Perron's (2003) results for structural breaks } \\
\hline \multicolumn{3}{|c|}{ ABSOLUTE returns } & \multicolumn{3}{|c|}{ SQUARED returns } \\
\hline Series & breaks & Break dates & Series & breaks & Break dates \\
\hline Bitcoin & 2 & $15 / 04 / 2014 ; 30 / 06 / 2017$ & Bitcoin & 3 & $\begin{array}{l}\text { 18/12/2014; } 17 / 12 / 2015 \\
09 / 11 / 2016\end{array}$ \\
\hline Bitshare & 2 & $03 / 02 / 2015 ; 15 / 12 / 2015$ & Bitshare & 2 & $03 / 02 / 2015 ; 15 / 12 / 2015$ \\
\hline Bytecoin & 2 & $27 / 02 / 2014 ; 08 / 02 / 2016$ & Bytecoin & 2 & $10 / 02 / 2015 ; 08 / 02 / 2016$ \\
\hline Dash & 1 & $04 / 12 / 2013$ & Dash & 1 & $04 / 12 / 2013$ \\
\hline Ether & 1 & $10 / 10 / 2013$ & Ether & 1 & $10 / 10 / 2013$ \\
\hline Litecoin & 3 & $\begin{array}{l}23 / 01 / 2014 ; 24 / 07 / 2015 \\
29 / 03 / 2017\end{array}$ & Litecoin & 1 & $23 / 01 / 2014$ \\
\hline Monero & 3 & $\begin{array}{l}14 / 02 / 2014 ; 16 / 07 / 2015 \\
09 / 02 / 2016\end{array}$ & Monero & 3 & $\begin{array}{l}02 / 12 / 2013 ; 16 / 07 / 2015 \\
14 / 07 / 2016\end{array}$ \\
\hline Nem & 3 & $\begin{array}{l}16 / 01 / 2014 ; 04 / 08 / 2014 \\
29 / 04 / 2015\end{array}$ & Nem & 1 & $01 / 04 / 2014$ \\
\hline Ripple & 2 & $14 / 02 / 2014 ; 09 / 12 / 2016$ & Ripple & 0 & ----- \\
\hline Siacoin & 3 & $\begin{array}{l}11 / 10 / 2013 ; 04 / 03 / 2014 \\
07 / 11 / 2014\end{array}$ & Siacoin & 0 & ----- \\
\hline Stellar & 3 & $\begin{array}{l}08 / 11 / 2013 ; 15 / 10 / 2014 \\
25 / 01 / 2016\end{array}$ & Stellar & 3 & $\begin{array}{l}08 / 11 / 2013 ; 16 / 10 / 2014 \\
01 / 09 / 2015\end{array}$ \\
\hline Tether & 0 & ----- & Tether & 0 & ----- \\
\hline
\end{tabular}




\section{Table 10: Estimates of $d$ for each subsample based on absolute returns}

\begin{tabular}{|c|c|c|c|c|}
\hline Series & Subsamples & No terms & An intercept & A linear time \\
\hline \multirow{4}{*}{ Bitcoin } & $1^{\text {st }}$ subsample & $0.21(0.14,0.30)$ & $0.21(0.14,0.29)$ & $0.20(0.14,0.30)$ \\
\hline & $2^{\text {nd }}$ subsample & $0.22(0.18,0.27)$ & $0.21(0.17,0.26)$ & $0.21(0.17,0.26)$ \\
\hline & $3^{\text {rd }}$ subsample & $0.04(-0.04,0.17)$ & $0.05(-0.05,0.17)$ & $0.04(-0.05,0.17)$ \\
\hline & $1^{\text {st }}$ subsample & $0.24(0.17,0.31)$ & $0.20(0.14,0.28)$ & $0.20(0.14,0.28)$ \\
\hline \multirow[t]{2}{*}{ Bitshare } & $2^{\text {nd }}$ subsample & $0.18(0.09,0.29)$ & $0.16(0.08,0.27)$ & $0.16(0.07,0.27)$ \\
\hline & $3^{\text {rd }}$ subsample & $0.21(0.11,0.33)$ & $0.19(0.10,0.31)$ & $0.19(0.10,0.31)$ \\
\hline \multirow{3}{*}{ Bytecoin } & $1^{\text {st }}$ subsample & $0.25(0.16,0.36)$ & $0.20(0.13,0.30)$ & $0.19(0.12,0.30)$ \\
\hline & $2^{\text {nd }}$ subsample & $0.18(0.11,0.26)$ & $0.18(0.11,0.26)$ & $0.18(0.11,0.25)$ \\
\hline & $3^{\text {rd }}$ subsample & $0.21(0.12,0.32)$ & $0.17(0.09,0.27)$ & $0.16(0.07,0.27)$ \\
\hline \multirow{2}{*}{ Dash } & $1^{\text {st }}$ subsample & $0.21(0.08,0.38)$ & $0.19(0.07,0.36)$ & $0.25(0.10,0.68)$ \\
\hline & $2^{\text {nd }}$ subsample & $0.20(0.16,0.25)$ & $0.19(0.15,0.24)$ & $0.19(0.15,0.24)$ \\
\hline \multirow{2}{*}{ Ether } & $1^{\text {st }}$ subsample & $0.41(0.21,0.71)$ & $0.41(0.20,0.78)$ & $0.45(0.22,0.80)$ \\
\hline & $2^{\text {nd }}$ subsample & $0.22(0.16,0.28)$ & $0.19(0.14,0.26)$ & $0.19(0.14,0.26)$ \\
\hline \multirow{3}{*}{ Litecoin } & $1^{\text {st }}$ subsample & $0.25(0.18,0.35)$ & $0.26(0.19,0.37)$ & $0.23(0.14,0.35)$ \\
\hline & $2^{\text {nd }}$ subsample & $0.19(0.13,0.26)$ & $0.18(0.12,0.25)$ & $0.18(0.12,0.25)$ \\
\hline & $3^{\text {rd }}$ subsample & $0.21(0.16,0.28)$ & $0.19(0.13,0.25)$ & $0.18(0.12,0.24)$ \\
\hline \multirow{5}{*}{ Monero } & $4^{\text {th }}$ subsample & $0.20(0.11,0.31)$ & $0.17(0.08,0.28)$ & $0.17(0.08,0.28)$ \\
\hline & $1^{\text {st }}$ subsample & $0.23(0.14,0.34)$ & $0.16(0.10,0.25)$ & $0.15(0.09,0.25)$ \\
\hline & $2^{\text {nd }}$ subsample & $0.20(0.13,0.29)$ & $0.20(0.13,0.28)$ & $0.19(0.13,0.28)$ \\
\hline & $3^{\text {rd }}$ subsample & $0.31(0.19,0.46)$ & $0.26(0.16,0.41)$ & $0.25(0.14,0.42)$ \\
\hline & $4^{\text {th }}$ subsample & $0.09(0.02,0.20)$ & $0.11(0.02,0.21)$ & $0.10(0.01,0.21)$ \\
\hline \multirow{4}{*}{ Nem } & $1^{\text {st }}$ subsample & $0.14(0.04,0.29)$ & $0.13(0.04,0.25)$ & $0.13(0.03,0.28)$ \\
\hline & $2^{\text {nd }}$ subsample & $0.21(0.12,0.33)$ & $0.19(0.11,0.30)$ & $0.19(0.11,0.30)$ \\
\hline & $3^{\text {rd }}$ subsample & $0.15(0.04,0.29)$ & $0.14(0.04,0.27)$ & $0.13(0.03,0.26)$ \\
\hline & $4^{\text {th }}$ subsample & $0.13(0.05,0.23)$ & $0.12(0.04,0.22)$ & $0.12(0.04,0.22)$ \\
\hline \multirow{3}{*}{ Ripple } & $1^{\text {st }}$ subsample & $0.24(0.17,0.33)$ & $0.21(0.15,0.29)$ & $0.20(0.13,0.29)$ \\
\hline & $2^{\text {nd }}$ subsample & $0.29(0.23,0.36)$ & $0.27(0.21,0.34)$ & $0.26(0.20,0.34)$ \\
\hline & $3^{\text {rd }}$ subsample & $0.28(0.21,0.36)$ & $0.28(0.22,0.36)$ & $0.28(0.22,0.36)$ \\
\hline \multirow{4}{*}{ Siacoin } & $1^{\text {st }}$ subsample & $0.24(0.09,0.45)$ & $0.23(0.09,0.43)$ & $0.22(0.08,0.43)$ \\
\hline & $2^{\text {nd }}$ subsample & $-0.05(-0.13,0.10)$ & $-0.06(-0.17,0.10)$ & $-0.07(-0.19,0.10)$ \\
\hline & $3^{\text {rd }}$ subsample & $0.16(-0.07,0.42)$ & $0.11(-0.04,0.37)$ & $0.08(-0.15,0.36)$ \\
\hline & $4^{\text {th }}$ subsample & $0.11(0.06,0.17)$ & $0.12(0.07,0.19)$ & $0.11(0.06,0.18)$ \\
\hline
\end{tabular}




\begin{tabular}{l|ccccccc} 
& $1^{\text {st }}$ subsample & $0.27(0.13,0.47)$ & $\mathbf{0 . 2 4}(\mathbf{0 . 1 1}, \mathbf{0 . 4 2})$ & $0.25(0.12,0.42)$ \\
Stellar & $2^{\text {nd }}$ subsample & $0.07(-0.02,0.18)$ & $\mathbf{0 . 0 7}(\mathbf{- 0 . 0 2}, \mathbf{0 . 1 8})$ & $0.07(-0.02,0.18)$ \\
& $3^{\text {rd }}$ subsample & $0.14(0.06,0.22)$ & $\mathbf{0 . 1 3}(\mathbf{0 . 0 6}, \mathbf{0 . 2 2})$ & $0.13(0.06,0.21)$ \\
\multirow{3}{*}{ Tether } & $4^{\text {th }}$ subsample & $0.26(0.15,0.40)$ & $\mathbf{0 . 2 3}(\mathbf{0 . 1 3}, \mathbf{0 . 3 6})$ & $0.25(0.14,0.38)$ \\
\hline
\end{tabular}

In parenthesis, the $95 \%$ confidence band of the non-rejection values of $\mathrm{d}$. In bold, the significant models according to the deterministic terms. 


\begin{tabular}{|c|c|c|c|c|}
\hline Series & $1^{\text {st }}$ subsample & $2^{\text {nd }}$ subsample & $3^{\text {rd }}$ subsample & $4^{\text {th }}$ subsample \\
\hline Bitcoin & $0.21(0.14,0.29)$ & $0.21(0.17,0.26)$ & $0.05(-0.05,0.17)$ & ----- \\
\hline Bitshare & $0.20(0.14,0.28)$ & $0.16(0.08,0.27)$ & $0.19(0.10,0.31)$ & ----- \\
\hline Bytecoin & $0.20(0.13,0.30)$ & $0.18(0.11,0.26)$ & $0.16(0.07,0.27)$ & ----- \\
\hline Dash & $0.25(0.10,0.68)$ & $0.19(0.15,0.24)$ & ----- & ----- \\
\hline Ether & $0.41(0.20,0.78)$ & $0.19(0.14,0.26)$ & ----- & ----- \\
\hline Litecoin & $0.23(0.14,0.35)$ & $0.18(0.12,0.25)$ & $0.18(0.12,0.24)$ & $0.17(0.08,0.28)$ \\
\hline Monero & $0.16(0.10,0.25)$ & $0.20(0.13,0.28)$ & $0.25(0.14,0.42)$ & $0.11(0.02,0.21)$ \\
\hline Nem & $0.13(0.04,0.25)$ & $0.19(0.11,0.30)$ & $0.14(0.04,0.27)$ & $0.12(0.04,0.22)$ \\
\hline Ripple & $0.21(0.15,0.29)$ & $0.27(0.21,0.34)$ & $0.28(0.22,0.36)$ & ----- \\
\hline Siacoin & $0.23(0.09,0.43)$ & $-0.06(-0.17,0.10)$ & $0.11(-0.04,0.37)$ & $0.11(0.06,0.18)$ \\
\hline Stellar & $0.24(0.11,0.42)$ & $0.07(-0.02,0.18)$ & $0.13(0.06,0.22)$ & $0.23(0.13,0.36)$ \\
\hline Tether & $0.27(0.22,0.32)$ & ----- & ----- & ----- \\
\hline
\end{tabular}

In parenthesis, the $95 \%$ confidence band of the non-rejection values of $\mathrm{d}$. 


\begin{tabular}{|c|c|c|c|c|}
\hline Series & Subsamples & No terms & An intercept & A linear time \\
\hline \multirow{5}{*}{ Bitcoin } & $1^{\text {st }}$ subsample & $0.24(0.18,0.32)$ & $0.23(0.17,0.30)$ & $0.23(0.17,0.30)$ \\
\hline & $2^{\text {nd }}$ subsample & $0.07(-0.03,0.18)$ & $0.05(-0.02,0.15)$ & $0.02(-0.07,0.14)$ \\
\hline & $3^{\text {rd }}$ subsample & $0.12(0.01,0.28)$ & $0.12(0.00,0.26)$ & $0.12(0.00,0.27)$ \\
\hline & 4rd subsample & $0.09(0.02,0.18)$ & $0.09(0.02,0.18)$ & $0.08(0.02,0.18)$ \\
\hline & $1^{\text {st }}$ subsample & $0.23(0.16,0.29)$ & $0.20(0.14,0.27)$ & $0.19(0.14,0.27)$ \\
\hline \multirow[t]{2}{*}{ Bitshare } & $2^{\text {nd }}$ subsample & $0.20(0.11,0.32)$ & $0.17(0.09,0.28)$ & $0.15(0.05,0.27)$ \\
\hline & $3^{\text {rd }}$ subsample & $0.21(0.11,0.33)$ & $0.19(0.10,0.31)$ & $0.19(0.10,0.31)$ \\
\hline \multirow{3}{*}{ Bytecoin } & $1^{\text {st }}$ subsample & $0.24(0.18,0.32)$ & $0.22(0.16,0.29)$ & $0.20(0.14,0.28)$ \\
\hline & $2^{\text {nd }}$ subsample & $0.20(0.12,0.30)$ & $0.18(0.11,0.28)$ & $0.19(0.11,0.28)$ \\
\hline & $3^{\text {rd }}$ subsample & $0.07(0.00,0.13)$ & $0.07(0.00,0.14)$ & $0.10(0.00,0.29)$ \\
\hline \multirow{2}{*}{ Dash } & $1^{\text {st }}$ subsample & $0.06(-0.05,0.13)$ & $0.05(-0.05,0.19)$ & $0.11(-0.02,0.36)$ \\
\hline & $2^{\text {nd }}$ subsample & $0.18(0.13,0.13)$ & $0.17(0.12,0.23)$ & $0.17(0.12,0.23)$ \\
\hline \multirow{2}{*}{ Ether } & $1^{\text {st }}$ subsample & $0.38(0.17,0.69)$ & $0.38(0.17,0.73)$ & $0.41(0.18,0.77)$ \\
\hline & $2^{\text {nd }}$ subsample & $0.14(0.08,0.20)$ & $0.13(0.08,0.19)$ & $0.13(0.08,0.19)$ \\
\hline \multirow{2}{*}{ Litecoin } & $1^{\text {st }}$ subsample & $0.15(0.07,0.25)$ & $0.15(0.07,0.26)$ & $0.11(0.02,0.24)$ \\
\hline & $2^{\text {nd }}$ subsample & $0.15(0.11,0.20)$ & $0.15(0.11,0.20)$ & $0.15(0.11,0.20)$ \\
\hline \multirow{4}{*}{ Monero } & $1^{\text {st }}$ subsample & $0.15(0.06,0.27)$ & $0.12(0.04,0.22)$ & $0.07(-0.02,0.18)$ \\
\hline & $2^{\text {nd }}$ subsample & $0.19(0.12,0.26)$ & $0.18(0.12,0.26)$ & $0.18(0.12,0.26)$ \\
\hline & $3^{\text {rd }}$ subsample & $0.34(0.22,0.50)$ & $0.31(0.20,0.46)$ & $0.31(0.20,0.46)$ \\
\hline & 4rd subsample & $0.02(-0.08,0.17)$ & $0.02(-0.08,0.16)$ & $0.03(-0.07$ \\
\hline \multirow[b]{2}{*}{ Nem } & $1^{\text {st }}$ subsample & $0.14(0.16,0.25)$ & $0.25(0.17,0.37)$ & $0.25(0.15,0.38)$ \\
\hline & $2^{\text {nd }}$ subsample & $0.05(-0.01,0.20)$ & $0.05(-0.01,0.11)$ & $0.05(-0.01,0.12)$ \\
\hline Ripple & No subsamples & $0.18(0.15,0.22)$ & $0.18(0.15,0.22)$ & $0.18(0.15,0.22)$ \\
\hline Siacoin & No subsamples & $0.12(0.17,0.23)$ & $0.11(0.16,0.22)$ & $0.11(0.16,0.22)$ \\
\hline \multirow{4}{*}{ Stellar } & $1^{\text {st }}$ subsample & $0.15(0.03,0.32)$ & $0.15(0.03,0.31)$ & $0.15(0.03,0.31)$ \\
\hline & $2^{\text {nd }}$ subsample & $0.06(-0.02,0.16)$ & $0.06(-0.02,0.16)$ & $0.06(-0.02,0.16)$ \\
\hline & $3^{\text {rd }}$ subsample & $0.22(-0.14,0.73)$ & $0.16(-0.10,0.55)$ & $0.22(-0.08,0.61)$ \\
\hline & 4rd subsample & $0.13(0.04,0.24)$ & $0.13(0.04,0.24)$ & $0.13(0.04,0.24)$ \\
\hline Tether & No subsamples & $0.16(0.12,0.22)$ & $0.17(0.12,0.22)$ & $0.15(0.09,0.21)$ \\
\hline
\end{tabular}




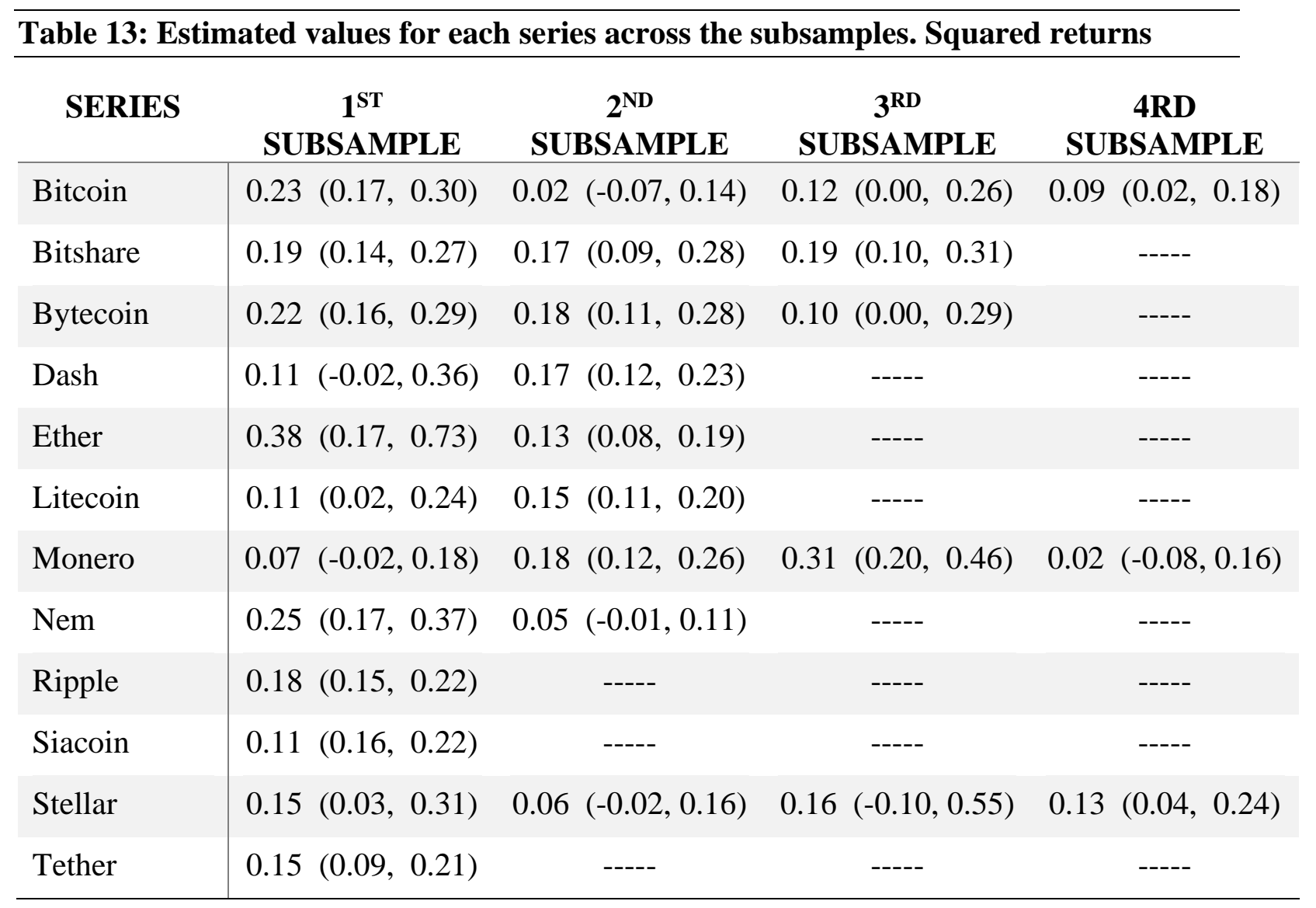

